\title{
Can Preoperative Complete Blood Count Parameters Be Used as Predictive Markers for Lymph Node Metastasis in Endometrial Carcinomas?
}

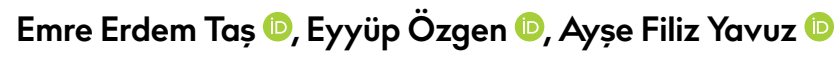 \\ Department of Obstetrics and Gynecology, Ankara Yıldırım Beyazıt University School of Medicine, Ankara, Turkey \\ ORCID IDs of the authors: E.E.T. 0000-000I-6043-2700; E.Ö. 0000-0003-2103-1853; A.F.Y. 0000-0003-3699-7757.
}

Cite this article as: Taș EE, Özgen E, Yavuz AF. Can Preoperative Complete Blood Count Parameters Be Used as Predictive Markers for Lymph Node Metastasis in Endometrial Carcinomas? Cyprus J Med Sci 2018; 3(3): 168-72.

\section{BACKGROUND/AIMS}

To investigate the clinical utility of complete blood count (CBC) parameters in the preoperative diagnosis of lymph node involvement (LNI) in endometrial carcinomas (ECs).

\section{MATERIAL and METHODS}

We conducted a retrospective study of 159 patients with ECs who underwent complete staging surgery at a tertiary center between 2007 and 2017. After demographic characteristics and preoperative CBC parameters were retrieved from the patients' medical records, the patients were grouped according to lymph node status (positive and negative) and compared. Variables with $p<0.05$ were included in the logistic regression analysis, and receiver operating characteristic curve analysis was used to determine the cut-off values for predicting LNI.

\section{RESULTS}

The mean age of the patients was 59.1 years, and 14 (8.8\%) patients had LNI. The mean white blood cell, neutrophil, and platelet counts; plateletcrit level; and neutrophil-to-lymphocyte and platelet-to-lymphocyte ratios were significantly higher in patients with LNI. Logistic regression analysis identified an independent association between increased neutrophil count and LNI (odds ratio 5.12; $\mathrm{p}<0.05$ ). The optimal cut-off value was $4.85\left(\times 10^{3} / \mu \mathrm{L}\right)$ (sensitivity, $77.4 \%$ and specificity, $\left.74.2 \%\right)$. A cut-off of $6.25\left(\times 10^{3} / \mu \mathrm{L}\right)$ was used to identify LNI with 100\% specificity.

\section{CONCLUSION}

An increased neutrophil count can be considered a useful additional tool for the preoperative diagnosis of LNI.

Keywords: Blood cell count, endometrial neoplasms, lymphatic metastasis, lymph node excision, neutrophils

\section{INTRODUCTION}

Endometrial carcinoma (EC) is the most common gynecological cancer among women in developed countries (I). Based on the GLOBOCAN estimates, which are produced by the International Agency for Research on Cancer, in 20I2, there were approximately 160,000 new cases worldwide (I). Moreover, as risk factors, including obesity and advancing age, become more prevalent, the incidence will likely increase. Fortunately, an early diagnosis can be made in many patients (approximately 75\%) based on signs and symptoms (abnormal uterine bleeding) (2).

Endometrial carcinoma is staged surgically and was first recognized by the International Federation of Gynecology and Obstetrics (FIGO) in 1988 (3). The staging guidelines were last revised in 2009, and total extrafascial hysterectomy, bilateral salpingo-oophorectomy, and pelvic and para-aortic lymph node dissection remain the standard staging procedures (3). Among the many clinical and pathological factors (FIGO stage, age, histological type and grade, tumor size, presence of lymphovascular space invasion (LVSI), lymph node involvement (LNI), and positive peritoneal cytology), the FIGO stage is the most important variable that influences the likelihood of EC recurrence and the survival rate (2). Therefore, the American Congress of Obstetricians and Gynecologists recommended surgical staging, including lymph node sampling, for all women with EC, except for those at increased risk of mortality because of secondary co- 
morbidities (4). Despite these recommendations, recent studies have generated much debate on the benefit of lymph node sampling in low-risk ECs (5-8). Owing to this debate, staging practices vary widely based on the individual physician and institutional practices. Nevertheless, it is difficult to identify ECs with LNI preoperatively. In an attempt to resolve this challenge, various tools, including serum carcinoma antigen 125 measurement and magnetic resonance imaging, have been used; however, the sensitivity and specificity of these techniques are varied $(7,9)$.

In contrast, studies of gynecological and non-gynecological cancers have shown that preoperative complete blood count (CBC) is a useful diagnostic tool for predicting $L N I$ and prognosis $(10,11)$. Similarly, studies conducted on ECs revealed that preoperative CBC parameters were not only able to predict cancerous lesions but might also be related to poor prognostic factors, including tumor stage and grade, LVSI, and LNI (I2-20). However, the clinical utility of CBC parameters for predicting LNI has not yet been widely investigated.

The aim of the present study was to determine whether there is any significant relationship between $\mathrm{LNI}$ and $\mathrm{CBC}$ parameters in ECs. Furthermore, we investigated the clinical utility of these parameters in the preoperative diagnosis of $\mathrm{LNI}$.

\section{MATERIAL and METHODS}

The medical files of 184 patients with EC who were staged surgically according to the recommendations of FIGO at a tertiary hospital between 2007 and 2017 were retrospectively analyzed. Patients who had acute inflammatory disease, myeloproliferative disorders, concomitant gynecological and other cancers, or autoimmune disease; were using any drug that affects $\mathrm{CBC}$ parameters including anticoagulants or hormonal contents; or

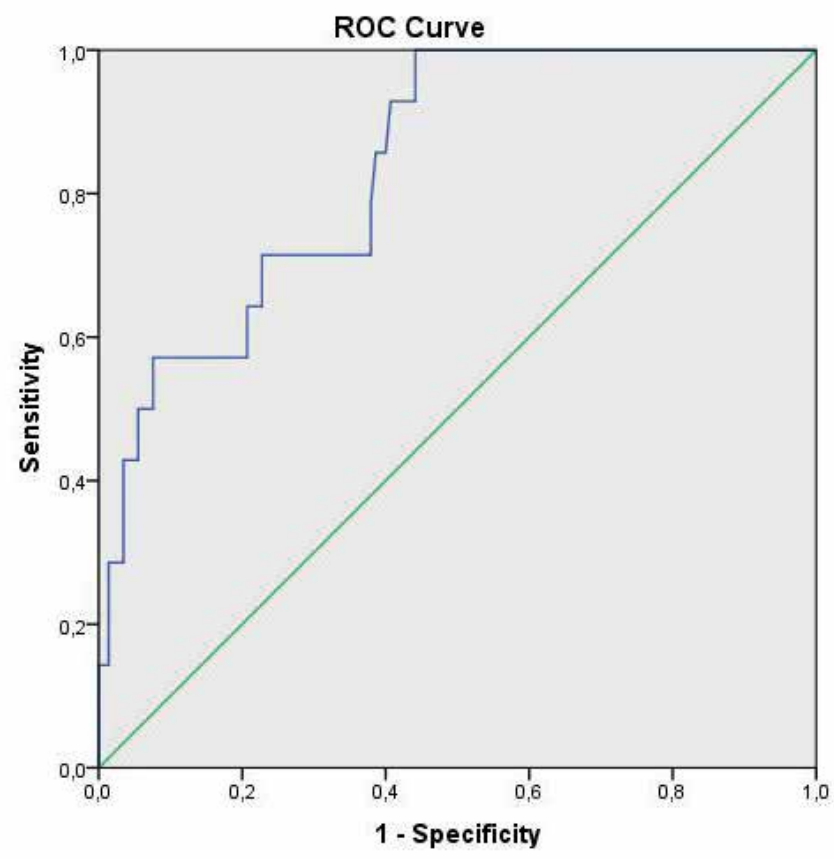

FIGURE I. Receiver operating characteristic curve of serum neutrophil levels for discriminating lymph node positive from lymph node negative patients with endometrial carcinoma (area under the curve: 0.838; standard error: 0.048) reported smoking were excluded from the study. A total of I59 patients were enrolled in the study. Informed oral consent was obtained from all participants. The study was approved by the Ethical Review Board of Ankara Atatürk Training and Research Hospital (approval no.: 26379996/152) and was conducted in accordance with the World Medical Association Declaration of Helsinki (2000 revision).

Data on demographic and pathological characteristics (age, gravidity, parity, histological type, FIGO stage, and LNI status) and preoperative CBC parameters (white blood cell (WBC), neutrophil, lymphocyte, and platelet counts; hemoglobin levels; mean corpuscular volume; mean platelet volume (MPV); platelet distribution width (PDW); plateletcrit levels; and neutrophil-to-lymphocyte (NLR) and platelet-to-lymphocyte (PLR) ratios) were retrieved from the patient's medical files and hospital records. Blood samples were collected when the patients were admitted to the hospital for surgery and before receiving any medications. Specimens were analyzed within $2 \mathrm{~h}$ using a Sysmex XE-2I00 Automated CBC Analyzer (Sysmex Europe, Germany).

After patients were grouped according to lymph node status (lymph node positive and lymph node negative), the groups were compared in terms of the examined CBC parameters. Once CBC parameters significantly associated with $L N I$ were determined, the clinical utility of those parameters in the preoperative diagnosis of LNI was investigated.

\section{Statistical Analysis}

Data were expressed as mean \pm standard deviation. The groups (lymph node positive vs. lymph node negative) were compared using independent sample t-tests. Variables with $p<0.05$ were included in the binary logistic regression analysis, and the influence of each factor on the preoperative diagnosis of LNI was evaluated. The receiver operating characteristic (ROC) curve analysis was used to determine the cut-off valves of the serum neutrophil level for diagnosing LNI. Statistical analyses were made using Statistical Package for the Social Sciences for Windows, version 21.0 (IBM, SPSS Corp.; Armonk, NY, USA). Odds ratios (ORs) and $95 \%$ confidence intervals (Cls) were determined. A $p<0.05$ was considered statistically significant.

\section{RESULTS}

Table I summarizes the demographic and pathological characteristics and preoperative CBC parameters of 159 patients with EC.

In the study group, 14 (8.8\%) patients had LNI. While the mean serum WBC, neutrophil, and platelet counts; plateletcrit level; and NLR and PLR ratios were significantly higher in the lymph node positive group than in the lymph node negative group $(p<0.05)$, the mean serum lymphocyte count and hemoglobin, hematocrit, MPV, and PDW levels did not differ significantly between the groups ( $p>0.05$ ) (Table 2).

Binary logistic regression analysis revealed that among variables that differed significantly between the lymph node positive and lymph node negative groups, only an increased neutrophil count was independently associated with LNI (OR 5.I2, 
95\% Cl 1.168-22.452; -=0.03) (Table 3). The ROC curve analysis revealed that the optimal cut-off value of the serum neutrophil level for predicting $\mathrm{LNI}$ was $4.85\left(\times 10^{3} / \mu \mathrm{L}\right)$. The sensitivity was $71.2 \%$, and the specificity was $74.2 \%$ (Fig. I). When the groups (lymph node positive vs. lymph node negative) were assessed in the ROC curve analysis using the $6.25\left(\times 10^{3} / \mu \mathrm{L}\right)$ cut-off value, the sensitivity was $51.1 \%$, and the specificity was $100 \%$.

TABLE I. Demographic and surgical characteristics and preoperative CBC parameters of 159 patients with endometrial carcinoma

\section{Characteristics}

Demographic and surgical, mean \pm SD (range)

Age (years)

Gravidity

Parity

Histological type, $\mathrm{n}(\%)$

Type I (endometrioid type)

$32(83.0)$

Type 2 (other types)a

$27(17.0)$

FIGO stage, $n(\%)$

IA

$97(61.0)$

IB

36 (22.6)

II

IIIA

IIIB

IIICl

IIIC2

IVA

IVB

Lymph node involvement, $\mathrm{n}(\%)$

Yes

No

145 (91.2)

$\mathrm{CBC}$ parameter, mean $\pm \mathrm{SD}$ (range)

WBC count $\left(\times 10^{3} / \mu \mathrm{L}\right)$

$7.772 \pm 1.975$

Neutrophil count $\left(\times 10^{3} / \mu \mathrm{L}\right)$

$4.426 \pm 1.535$

Lymphocyte count $\left(\times 10^{3} / \mu \mathrm{L}\right)$

$2.231 \pm 0.645$

Hemoglobin $(\mathrm{g} / \mathrm{dL})$

$12.858 \pm 1.56$

Hematocrit (\%)

$38.91 \pm 4.312$

$\mathrm{MCV}(\mathrm{fL})$

$84.67 \pm 6.27$

Platelet count $\left(\times 10^{3} / \mu \mathrm{L}\right)$

$288.415 \pm 81.072$

$M P V(f L)$

$10.33 \pm 1.4 \mid$

PDW (fL)

$14.0 \pm 2.57$

Plateletcrit (\%)

$0.293 \pm 0.830$

$\operatorname{NLR}(\%)$

$2.180 \pm 1.193$

PLR (\%)

$140.155 \pm 60.59$

Type II tumors include serous, clear cell, mucinous, mixed, and undifferentiated histological subtypes.

CBC: complete blood count; FIGO: International Federation of Gynecology and Obstetrics; MCV: mean corpuscular volume; MPV: mean platelet volume; NLR: neutrophil-to-lymphocyte ratio; PLR: platelet-to-lymphocyte ratio; PDW: platelet distribution width; SD: standard deviation; WBC: white blood cell

\section{DISCUSSION}

The present study has shown that various CBC parameters, including WBC, neutrophil, and platelet counts; plateletcrit level; and NLR and PLR ratios, were significantly higher in ECs with LNI. Furthermore, it revealed that the neutrophil count was an independent predictor of a preoperative diagnosis of $\mathrm{LNI}$, and a value $>6.25\left(\times 10^{3} / \mu \mathrm{L}\right)$ was able to identify ECs with $\mathrm{LNI}$ with a specificity of $100 \%$. To our knowledge, this is the first study that widely investigates the clinical utility of $\mathrm{CBC}$ parameters for diagnosing ECs with LNI.

The influence of inflammation, caused by inflammatory cells and their mediators, in various aspects of cancer, including cancer initiation, promotion, progression, and metastasis, has recently been demonstrated (2I). Similarly, it is suggested that changes in serum CBC parameters, including cell counts, cell size and shape, and cell-to-cell ratios, may reflect cancer and cancer-related characteristics. Studies of ECs revealed that various CBC parameters, such as WBC count, platelet count, PDW,

TABLE 2. The CBC parameters of patients with endometrial carcinomas according to lymph node status (positive or negative)

\begin{tabular}{|c|c|c|c|}
\hline $\begin{array}{l}\text { Characteristics, } \\
\text { mean }( \pm S D)\end{array}$ & $\begin{array}{c}\text { Lymph node } \\
\text { positive } \\
(n=\mid 4,9.8 \%)\end{array}$ & $\begin{array}{c}\text { Lymph node } \\
\text { negative } \\
(n=\mid 45,91.2 \%)\end{array}$ & $\mathbf{p}$ \\
\hline WBC count $\left(\times 10^{3} / \mu \mathrm{L}\right)$ & $9.492 \pm 2.123$ & $7.611 \pm 1.887$ & $0.001^{*}$ \\
\hline Neutrophil count $\left(\times 10^{3} / \mu \mathrm{L}\right)$ & $6.307 \pm 1.541$ & $4.244 \pm 1.402$ & $<0.001^{*}$ \\
\hline Lymphocyte count $\left(\times \mid 0^{3} / \mu \mathrm{L}\right)$ & $2.067 \pm 0.598$ & $2.247 \pm 0.649$ & 0.321 \\
\hline Hemoglobin (g/dL) & $12.342 \pm 1.364$ & $12.904 \pm 1.572$ & 0.199 \\
\hline Hematocrit (\%) & $38.0 \pm 4.655$ & $38.996 \pm 4.284$ & 0.414 \\
\hline$M C V(f L)$ & $86.535 \pm 6.047$ & $84.495 \pm 6.047$ & 0.246 \\
\hline Platelet count $\left(\times \mid 0^{3} / \mu \mathrm{L}\right)$ & $358.642 \pm 76.436$ & $281.634 \pm 78.476$ & $0.001^{*}$ \\
\hline$M P V(f L)$ & $10.385 \pm 1.224$ & $10.325 \pm 1.43$ & 0.879 \\
\hline PDW (fL) & $13.964 \pm 2.45$ & $14.0 \pm 2.595$ & 0.953 \\
\hline Plateletcrit (\%) & $0.34 \pm 0.11$ & $0.288 \pm 0.079$ & $0.026^{*}$ \\
\hline $\operatorname{NLR}(\%)$ & $3.285 \pm 1.155$ & $2.075 \pm 1.145$ & $<0.001^{*}$ \\
\hline $\operatorname{PLR}(\%)$ & $192.723 \pm 84.075$ & $135.044 \pm 55.602$ & $0.001^{*}$ \\
\hline
\end{tabular}

\section{${ }^{*} p<0.05$.}

CBC: complete blood count; MCV: mean corpuscular volume; MPV: mean platelet volume; NLR: neutrophil-to-lymphocyte ratio; PLR: platelet-to-lymphocyte ratio; PDW: platelet distribution width; SD: standard deviation; WBC: white blood cell

TABLE 3. Binary logistic regression analysis of $C B C$ variables of patients with respect to lymph node involvement

$\begin{array}{lccc}\text { Variables } & \mathbf{P} & \text { OR } & \mathbf{9 5 \% ~ C l} \\ \text { WBC count } & 0.855 & 1.052 & 0.613-1.804 \\ \text { Neutrophil count } & 0.03^{*} & 5.12 & 0.168-22.452 \\ \text { Platelet count } & 0.675 & 0.996 & 0.975-1.016 \\ \text { Plateletcrit } & 0.155 & 0.001 & 0.001-33.417 \\ \text { NLR } & 0.214 & 0.202 & 0.016-2.516 \\ \text { PLR } & 0.095 & 1.033 & 0.994-1.074 \\ \text { *p<0.05. } & & & \\ \begin{array}{l}\text { CBC: complete blood count; Cl: confidence interval; NLR: neutro- } \\ \text { phil-to-lymphocyte ratio; OR: odds ratio; PLR: platelet-to-lymphocyte } \\ \text { ratio; WBC: white blood cell }\end{array}\end{array}$


MPV, plateletcrit, and NLR, were significantly higher in ECs than in healthy and precancerous controls (12-17). Furthermore, some studies reported that serum WBC count, platelet count, and $M P V$ may reflect both tumor stage and grade in $\operatorname{ECs}(12,13,17,18)$. As a result, the authors proposed that $\mathrm{CBC}$ is a useful diagnostic tool for the preoperative early diagnosis of ECs in patients at a high risk of EC (i.e., those with abnormal uterine bleeding) (12-16).

Furthermore, several recent studies have investigated the relationship between CBC and LNI in ECs (I3, 18-20). However, their results were inconsistent. For instance, Ekici et al. (I3) found that both WBC and platelet counts are significantly higher in ECs with LNI than in others. Conversely, Takahashi et al. (18) found a significant relationship between increased platelet count and LNI, whereas there was no significant relationship between WBC count and LNI (19). In contrast, in their study, Suh et al. (20) found significant relationships between both NLR and PLR ratios and $L N I$, whereas there was no significant relationship between WBC count and LNI. In the present study, we found that preoperative serum WBC, platelet, and neutrophil counts; plateletcrit level; and PLR and NLR ratios were significantly higher in ECs with LNI. Furthermore, our study revealed that the neutrophil count was an independent predictor of the preoperative diagnosis of LNI.

An increased serum neutrophil count has been observed in many cancers with an advanced tumor stage and a poor prognosis $(22,23)$. Although the precise mechanism is still unknown, this condition was proposed to provide evidence for the concept of cancer-related inflammation inducing tumor progression (23, 24). Takahashi et al. (18) also found significant relationships between an increased neutrophil count and various poor prognostic factors associated with ECs (advanced surgical stage, LVSI, and cervical stromal involvement). In contrast to the previous study, the present study showed a significant and independent relationship between an increased neutrophil count and LNI. The inconsistency between studies may be the result of the diverse surgical and histological characteristics of the study populations, including FIGO stage and histological type and grade. It may also be the result of many variable characteristics of the study populations (i.e. race and harvested lymph node count).

Currently, there is no consensus on the benefit of lymph node sampling in all patients with ECs. Although a population-based retrospective study stated that lymph node sampling improved the survival of patients with ECs, another recent prospective study found no evidence of benefit from lymph node sampling in terms of overall or recurrence-free survival in women with early stage disease $(3,4)$. Thus, identification of patients with a high risk of LNI may improve survival by determining the extent of the lymph node sampling area and the administration of a suitable adjuvant therapy. With this aim, the usability of various diagnostic tools has been investigated. However, the sensitivity and specificity of commonly used preoperative diagnostic tools for $\mathrm{LNI}$, such as serum carcinoma antigen 125 and magnetic resonance imaging, have been reported to be approximately $61.5 \%$ $77.8 \% / 81.0 \%-94.9 \%$ and $50.0 \%-62.2 \% / 92.0 \%-94.9 \%$, respectively $(7,9)$. Similarly, the present study showed that the neutrophil count had $71.2 \%$ sensitivity and $74.2 \%$ specificity for diagnosing ECs with LNI preoperatively. Additionally, a cut-off value of 6.25 $\left(\times 10^{3} / \mu \mathrm{L}\right)$ was able to identify patients with EC with $\mathrm{LNI}$ with $100 \%$ specificity.
In conclusion, although the present study has its limitations, such as its retrospective single-center design and relatively small sample size, it revealed the potential predictive role of $\mathrm{CBC}$ for selecting patients with EC with LNI. To our knowledge, the present study is also the first to report the usability of the neutrophil count for diagnosing ECs with LNI. As the neutrophil level can be routinely determined using CBC tests preoperatively, this low cost and readily available parameter may be a new and promising marker to select patients with ECs for extended lymph node sampling. However, comprehensive studies on different histological subtypes are necessary to determine the utility of this marker for patients with ECs.

Ethics Committee Approval: Ethics committee approval was received for this study from Ankara Atatürk Training and Research Hospital. (Approval Date: 28/05/2018, Approval Number: 26379996/I52).

Informed Consent: Oral informed consent was taken from the patients prior to the study.

Peer-review: Externally peer-reviewed.

Author contributions: Concept - E.E.T., E.Ö., A.F.Y.; Design - E.E.T., E.Ö., A.F.Y.; Supervision - E.E.T., E.Ö., A.F.Y.; Resource - E.E.T., E.Ö., A.F.Y.; Materials - E.E.T.; Data Collection and/or Processing - E.E.T., E.Ö.; Analysis and/ or Interpretation - E.E.T., A.F.Y.; Literature Search - E.E.T., E.Ö.; Writing E.E.T., E.Ö., A.F.Y.; Critical Reviews - A.F.Y.

Conflict of Interest: The authors have no conflicts of interest to declare.

Financial Disclosure: The authors declared that this study has received no financial support.

\section{REFERENCES}

I. Torre LA, Bray F, Siegel RL, Ferlay J, Lortet-Tieulent J, Jemal A. Global cancer statistics, 2012. CA Cancer J Clin 2015; 65: 87-I08. [CrossRef]

2. Creasman WT, Odicino F, Maisonneuve P, Quinn MA, Beller U, Benedet JL, et al. Carcinoma of the corpus uteri. FIGO 26th Annual Report on the Results of Treatment in Gynecological Cancer. Int J Gynaecol Obstet 2006; 95(Suppl I): SI05-43 [CrossRef]

3. Werner HM, Trovik J, Marcickiewicz J, Tingulstad S, Staff AC, Amant $\mathrm{F}$, et al. Revision of FIGO surgical staging in 2009 for endometrial cancer validates to improve risk stratification. Gynecol Oncol 2012; 125: 103-8. [CrossRef]

4. Practice Bulletin No. 149: Endometrial cancer. Obstet Gynecol 2015; 125: 1006-26. [CrossRef]

5. Milam MR, Java J, Walker JL, Metzinger DS, Parker LP, Coleman RL, et al. Nodal metastasis risk in endometrioid endometrial cancer. Obstet Gynecol 2012; 119: 286-92. [CrossRef]

6. Frost JA, Webster KE, Bryant A, Morrison J. Lymphadenectomy for the management of endometrial cancer. Cochrane Database Syst Rev 2015; 10: CD007585. [CrossRef]

7. Kang S, Nam JH, Bae DS, Kim JW, Kim MH, Chen X, et al. Preoperative assessment of lymph node metastasis in endometrial cancer: $A$ Korean Gynecologic Oncology Group study. Cancer 2017; 123: 26372. [CrossRef]

8. Vergas R, Rauh-Hain JA, Clemmer J, Clark RM, Goodman A, Growdon WB, et al. Tumor size, depth of invasion, and histologic grade as prognostic factors of lymph node involvement in endometrial cancer: a SEER analysis. Gynecol Oncol 2014; 133: 216-20. [CrossRef]

9. Andreano A, Rechichi G, Rebora P, Sironi S, Valsecchi MG, Galimberti S. MR diffusion imaging for preoperative staging of myometrial invasion in patients with endometrial cancer: a systematic review and meta-analysis. Eur Radiol 2014; 24: 1327-38. [CrossRef] 
10. Ertas IE, Gungorduk K, Akman L, Ozdemir A, Terek MC, Ozsaran A, et al. Can preoperative neutrophil:lymphocyte and platelet:lymphocyte ratios be used as predictive marker for lymph node metastasis in squamous cell carcinoma of the vulva? Eur J Obstet Gynecol Reprod Biol 2013; 171: 138-42. [CrossRef]

II. D'Andrea D, Moschini M, Gust KM, Abufaraj M, Özsoy M, Mathieu $\mathrm{R}$, et al. Lymphocyte-to-monocyte ratio and neutrophil-to-lymphocyte ratio as biomarkers for predicting lymph node metastasis and survival in patients treated with radical cyctectomy. J Surg Oncol 2017; II5: 455-6I. [CrossRef]

12. Kemal Y, Demirag G, Baș B, Önem S, Teker F, Yücel I. The value of red blood cell distribution width in endometrial cancer. Clin Chem Lab Med 2015; 53: 823-7. [CrossRef]

13. Ekici H, Malatyalioglu E, Kokcu A, Kurtoglu E, Tosun M, Celik H. Do leukocyte and platelet counts have benefit for preoperative evalvation of endometrial cancer? Asian Pac J Cancer Prev 2015; 16: 5305-I0. [CrossRef]

14. Karateke A, Kaplanoglu N, Baloglu A. Relations of platelet indices with endometrial hyperplasia and endometrial cancer. Asian Pac J Cancer Prev 2015; 16: 4905-8. [CrossRef]

15. Acmaz G, Aksoy H, Unal D, Ozyurt S, Cingillioglu B, Aksoy U, et al. Are neutrophil/lymphocyte and platelet/lymphocyte ratios associated with endometrial precancerous and cancerous lesions in patients with abnormal uterine bleeding? Asian Pac J Cancer Prev 2014; 15: 1689-92. [CrossRef]

16. Ural ÜM, Șehitoğlu I, Tekin YB, Șahin FK. Neutrophil-to-lymphocyte and platelet-to-lymphocyte ratios in patients with endometrial hy- perplasia and endometrial cancer. J Obstet Gynaecol Res 2015; 4I: 445-8. [CrossRef]

17. Oge T, Yalcin OT, Ozalp SS, Isikci T. Platelet volume as a parameter for platelet activation in patients with endometrial cancer. J Obstet Gynaecol 2013; 33: 30I-4. [CrossRef]

18. Takahashi R, Mabuchi S, Kawano M, Sasano T, Matsumoto Y, Kuroda $\mathrm{H}$, et al. Prognostic significance of systemic neutrophil and leukocyte alterations in surgically treated endometrial cancer patients: a mono institutional study. Gynecol Oncol 2015; I37: 112-8. [CrossRef]

19. Takahashi R, Mabuchi S, Kuroda H, Kozasa K, Yokoi E, Matsumoto Y, et al. The significance of pretreatment thrombocytosis and its association with neutrophilia in patients with surgically treated endometrial cancer. Int J Gynecol Cancer 2017; 27: 1399-407. [CrossRef]

20. Suh DH, Kim HS, Chung HH, Kim JW, Park NH, Song YS, Kang SB. Pre-operative systemic inflammatory response markers in predicting lymph node metastasis in endometrioid endometrial adenocarcinoma. Eur J Obstet Gynecol Reprod Biol 2012; 162: 206-I0. [CrossRef]

21. Mantovani A, Allavena P, Sica A, Balkwill F. Cancer-related inflammation. Nature 2008; 454: 436-44. [CrossRef]

22. Zhao W, Wang $P$, Jia $H$, Chen M, Gu X, Liu M, et al. Neutrophil count and percentage: potential independent prognostic indicators for advanced cancer patients in a palliative care setting. Oncotarget 2017; 8: 64499-508. [CrossRef]

23. Uribe-Querol E, Rosales C. Neutrophils in cancer: two sides of the same coin. J Immunol Res 2015; 2015: 983698. [CrossRef]

24. Hanahan D, Weinberg RA. Hallmarks of cancer: the next generation. Cell 20II; 144: 646-74. doi: 10.1016/i.cell.2011.02.013. [CrossRef] 